\title{
Thermotropic Ionic Liquid Crystals via Self-Assembly of Cationic Hyperbranched Polypeptides and Anionic Surfactants
}

\author{
Nadia Canilho, ${ }^{\dagger}$ Markus Scholl, ${ }^{\ddagger}$ Harm-Anton Klok, ${ }^{*}$, and Raffaele Mezzenga ${ }^{*}, \dagger, \S$ \\ Department of Physics and Fribourg Center for Nanomaterials, University of Fribourg, \\ Ch. du Musée 3, CH-1700 Fribourg, Switzerland, Laboratoire des Polymères, Institut des Matériaux, \\ Ecole Polytechnique Fédérale de Lausanne, Bâtiment MXD, STI-IMX-LP, Station 12, \\ CH-1015 Lausanne, Switzerland, and Nestlé Research Center, Vers-Chez-les-Blancs, \\ 1000 Lausanne 26, Switzerland
}

\begin{abstract}
This work describes the dilute solution and solid-state structure of polyelectrolyte complexes generated from hyperbranched polylysine (HBPL) and various anionic, sodium alkyl sulfate surfactants. In dilute solution, the radius of gyration $\left(R_{\mathrm{g}}\right)$ of the HBPL and HBPL - surfactant complexes was determined in the Guinier regime in good solvent conditions by means of small-angle X-ray scattering (SAXS). With increasing molecular weight of the HBPL, an increase in $R_{\mathrm{g}}$ up to a maximum of 3.7 and $4.2 \mathrm{~nm}$ was observed for the HBPLs and HBPL-surfactant complexes, respectively. In the solid state, HBPL-surfactant complexes were found to form liquid crystalline (LC) phases, whose thermal stability and structure depended both on the molecular weight of the HBPL as well as on the nature of the anionic surfactant. Depending on the surfactant alkyl chain length, liquid crystalline phases with short range liquid-like order, columnar hexagonal packing or lamellar ordering were observed. By combination of small-angle X-ray scattering, differential scanning calorimetry (DSC), and cross-polarized light optical microscopy $(\mathrm{CPOM})$, the exact structure of the LC phases, as well as their region of thermal stability, could be identified. HBPL-sodium dodecyl sulfate LC phases showed thermotropic behavior and underwent two transitions with increasing temperature. First, at lower temperatures, an order-nematic transition was observed. Upon further temperature increase, a second transition from a nematic to an isotropic phase was observed. Structural models for these different LC phases are proposed.
\end{abstract}

\section{Introduction}

The use of polymeric block sequences to design linear block copolymers or comblike polymers has been deeply explored during the last 25 years in soft condensed matter as a valuable technique to rationally design nanostructured materials based on the segregation of the different blocks. ${ }^{1-3}$ In block copolymer systems, for example, by varying the number and sequences of different blocks one can virtually access a very large panel of mesophases. ${ }^{4}$ The complexity of the phase diagram and the mesomorphism of these self-assembled materials depend directly on the molecular architecture of the macromolecular templates. This approach has, however, the main disadvantage to increase the complexity of the synthetic routes needed to design suitable polymeric molecules. Supramolecular chemistry has been emerging during the past decade as an alternative route in which macromolecules of a certain complexity can be designed by assembling simpler building blocks which are held together by, e.g., hydrogen bonding or ionic interactions. ${ }^{5-9}$ Not only does this technique offer the advantage to handle molecules and macromolecules of reduced complexity, but it also enables to exploit the reversibility of hydrogen or ionic bonds to control the morphology of segregated structures and allows the design of reversible or stimuli-responsive segregated nanostructures. ${ }^{10,11}$

* Corresponding authors. (R.M. at the University of Fribourg) E-mail: raffaele.mezzenga@unifr.ch. Telephone: +4126300 9066. Fax: +41 26 300 9747. (R.M. at the Nestlé Research Center) E-mail: raffaele.mezzenga@ rdls.nestle.com. Telephone: +41 21785 8078. Fax: +41 217858554 . (H.-A.K.) E-mail: harm-anton.klok@epfl.ch, Telephone: +41 216934866. Fax: + 41216935650 .

Department of Physics and Fribourg Center for Nanomaterials.

† Laboratoire des Polymères, Institut des Matériaux, École Polytechnique Fédérale de Lausanne.

${ }^{\S}$ Nestlé Research Center.
The hydrogen-bonding strategy has been applied mostly to linear homopolymers and block copolymers to design macromolecular templates in which the polymer backbone acts as a hydrogenbonding acceptor and surfactants act as hydrogen-bonding donors so that hairy comblike polymers are formed in which the segregation between the surfactant and the polymer backbone leads to the final morphology. ${ }^{12}$ In the case of ionic complexation, various polyelectrolyte architectures have been considered, such as linear, hyperbranched, dendritic, and dendronized polymers, ${ }^{8,13,14,15}$ while hydrocarbon-based surfactants and rigid rods have been the mostly investigated classes of ionic surfactants. ${ }^{16,17}$ The resulting polyelectrolyte-surfactant complexes have been shown to microphase segregate into liquid crystalline mesophases, analogous to those obtained in systems where the mesogenic units are covalently attached to macromolecules. ${ }^{18-24}$

Bioinspired complexes based on ionic complexation of polypeptides and phospholipids have been recently reported using both peptide homopolymers and block copolymers, leading to a rich polymorphism, including lamellar, tetragonal $^{14,15}$ or rectangular ${ }^{14,25}$ mesophases. Furthermore, in contrast to peptidic polymers covalently modified with mesogenic units, ${ }^{26,27}$ polypeptide-surfactant complexes are expected to be $\mathrm{pH}$ responsive and thus offer a very promising pathway to design $\mathrm{pH}$-responsive mesostructures. ${ }^{28}$ In such an approach, the exact liquid crystalline phase designed using supramolecular assemblies of polypeptides and lipids can in principle be controlled by a large number of factors such as the structure of the lipid, the architecture of the polypeptide, and the $\mathrm{pH}$.

Most of the studies reported up to date on polypeptide-alkyl tail ionic complexes have focused on the liquid and solid-state properties of linear homopolypeptides and related block copolymers. ${ }^{29-34}$ In the present work, we report for the first 
Table 1. Number-Average and Weight-Average Molecular Weights $\left(M_{\mathrm{n}}\right.$ and $\left.M_{\mathrm{w}}\right)$, Polydispersity $\left(M_{\mathrm{w}} / M_{\mathrm{n}}\right)$ and Number-Average Degree of Polymerization (DP) for the Hyperbranched Polypeptides Used, Degree of Loading of Surfactants onto HBPL Polymers as Obtained by ${ }^{1} \mathrm{H}$ NMR Analysis for HBPL-C8 and HBPL-C12 Complexes ${ }^{a}$

\begin{tabular}{|c|c|c|c|c|c|c|c|c|c|}
\hline \multirow[b]{3}{*}{ sample } & \multirow[b]{3}{*}{$\begin{array}{c}M_{\mathrm{n}} \\
{[\mathrm{g} / \mathrm{mol}]}\end{array}$} & \multirow[b]{3}{*}{$\begin{array}{c}M_{\mathrm{w}} \\
{[\mathrm{g} / \mathrm{mol}]}\end{array}$} & \multirow[b]{3}{*}{$M_{\mathrm{w}} / M_{\mathrm{n}}$} & \multirow[b]{3}{*}{ DP } & \multicolumn{5}{|c|}{ degree of loading } \\
\hline & & & & & \multirow[b]{2}{*}{$\begin{array}{c}\mathrm{C} 8 \\
R=1\end{array}$} & \multicolumn{4}{|c|}{$\mathrm{C} 12$} \\
\hline & & & & & & $R=0.4$ & $R=0.64$ & $R=1.05$ & $R=1.58$ \\
\hline HBPL $_{3600}$ & 3600 & 9600 & 2.6 & 28 & $0.75 \pm 0.04$ & & & $0.80 \pm 0.04$ & \\
\hline $\mathrm{HBPL}_{3800}$ & 3800 & 6800 & 1.9 & 30 & & & & $0.92 \pm 0.05$ & \\
\hline $\mathrm{HBPL}_{4400}$ & 4400 & 24300 & 5.5 & 34 & & & & $0.87 \pm 0.04$ & \\
\hline $\mathrm{HBPL}_{7500}$ & 7500 & 29600 & 3.9 & 59 & $0.91 \pm 0.05$ & $1 \pm 0.05$ & $1 \pm 0.05$ & $0.95 \pm 0.05$ & $0.94 \pm 0.05$ \\
\hline HBPL $_{7600}$ & 7600 & 72200 & 9.5 & 60 & & & & $0.86 \pm 0.04$ & \\
\hline HBPL $_{9400}$ & 9400 & 32900 & 3.5 & 73 & & & & $0.88 \pm 0.04$ & \\
\hline HBPL $_{9600}$ & 9600 & 88000 & 9.2 & 75 & $0.86 \pm 0.04$ & & & $0.90 \pm 0.05$ & \\
\hline
\end{tabular}
${ }^{a}$ The molecular ratio of complexation $(R)$ is the molar ratio between anionic surfactants and the amino groups of the $\mathrm{HBPL} R=c\left[\mathrm{SO}_{4}{ }^{-}\right] / c\left[\mathrm{NH}_{3}{ }^{+}\right]$used
during complex preparation.

time the dilute solution properties, as well as bulk solid state behavior of polyelectrolyte complexes obtained from cationic hyperbranched polylysines and anionic sodium alkyl sulfate surfactants of various alkyl tail lengths. These supramolecular complexes represent a model system for studying more sophisticated globular protein-lipid complexes in the colloidal regime. Furthermore, the presence of a polypeptide with an hyperbranched backbone introduces novel unexplored scenarios in the self-assembly mechanisms of the complex in the solid-state such as the following: (i) suppression of possible secondary structures in the polypeptide backbone as a consequence of branching units; (ii) introduction of an intrinsic polymer/ surfactant curvature as a consequence of the "globular" nature of the hyperbranched polyelectrolyte. As it will be shown later on, this is anticipated to have important consequences on the type of liquid crystalline phases observed in the solid state.

In what follows, we discuss the effect of both the polyelectrolyte and surfactant molecular weight and their consequences on the design of both single supramolecules and their bulk selfassembled structure. Finally, based on experimental characterization, we propose a structural model for the organization of hyperbranched polymer-surfactant liquid crystals in solid state which is in agreement with their thermotropic behavior.

\section{Experimental Section}

2.1. Materials. Milli-Q water and 1-butanol (analytical grade) were used as received from Fluka. Sodium octyl sulfate (C8, Fluka, 95\%), sodium dodecyl sulfate (C12, Fluka, 98\%), and sodium octadecyl sulfate (C18, Fluka, $98 \%$ ) were used as received. The critical micelle concentrations $(\mathrm{cmc})$ of these surfactants are 0.10 and $0.134 \mathrm{M}^{35}$ for $\mathrm{C} 12$ and $\mathrm{C} 8$, respectively. $\mathrm{C} 18$, for which the $\mathrm{cmc}$ value is not reported in the literature, showed poor solubility in water. $\mathrm{CD}_{3} \mathrm{OD}$ for NMR spectroscopy was acquired from Armar Chemicals (Döttigen, Switzerland). Hyperbranched polylysines (HBPL) were synthesized according to the procedure described elsewhere. ${ }^{36}$ Samples of different molecular weights were obtained via dialysis, using membranes with different molecular weight cut-offs. The number- and weight-average molecular weights and the polydispersities of the different samples are listed in Table 1. The glass transition temperature $\left(T_{\mathrm{g}}\right)$ of these polymers is $\sim 38$ ${ }^{\circ} \mathrm{C}$. In acidic aqueous solution, the HBPLs are positively charged due to the $\mathrm{p} K_{\mathrm{a}} \mathrm{s}$ of 10.28 and 8.90 of the amino groups of the lysine.

2.2. Methods. Gel Permeation Chromatography (GPC). Gel permeation chromatography to determine the molecular weights of the polymers was performed on a Waters $150 \mathrm{CV}$ instrument modified for on-line differential viscosimetry. All analyses were carried out at $30{ }^{\circ} \mathrm{C}$ using two Shodex OHPak columns (SB-803HQ + SB-804HQ) in series using $0.1 \mathrm{M} \mathrm{NaHCO}_{3}$ as eluent at a flow rate of $0.5 \mathrm{~mL} / \mathrm{min}$. Elution times were converted into absolute molecular weights using the "universal calibration" curve, which was constructed using poly(ethylene oxide) standards with a narrow molecular weight distribution. Sample elution was monitored with a UV-detector at a wavelength of $230 \mathrm{~nm}$. In addition, molecular weights of selected hyperbranched polylysine samples were measured by triple detection GPC (refractive index/viscometry/light scattering). The results indicated a good agreement between the data obtained using light scattering and the "universal calibration" method. ${ }^{37}$

Nuclear Magnetic Resonance (NMR). ${ }^{1} \mathrm{H}$ and ${ }^{13} \mathrm{C}$ NMR spectra were recorded at room temperature on a Bruker Avance 400 spectrometer. All spectra were measured in $\mathrm{CD}_{3} \mathrm{OD}$ and were calibrated using $0.03 \% \mathrm{v} / \mathrm{v}$ TMS as reference.

Fourier Transform Infrared Spectroscopy (FTIR). Fourier transform infrared spectra were recorded with a Bomem Hartmann and Braun MB 155 FTIR spectrometer in attenuated total reflection (ATR) mode with a $\mathrm{ZnSe}$ crystal in the spectral region of 600$4000 \mathrm{~cm}^{-1}$ with a resolution of $2 \mathrm{~cm}^{-1}$. In order to achieve good contact with the cell, the sample was compressed to form a platelet and placed directly in contact with the crystal.

Cross-Polarized Optical Microscopy (CPOM). Birefringence of the complexes was investigated using a Leica DMLB microscope equipped with polarizing filters and a JVC digital TK-C138050 color video camera. Films of the samples were cast on a microscope glass from a $4 \%$ (by weight) solution of the complexes in 1-butanol. The films were predried overnight before being annealed during 3 days at $10^{-8}$ mbar at $60^{\circ} \mathrm{C}$ for complexes HBPL $3600^{-} \mathrm{C} 8$, HBPL $\mathrm{H}_{360}-$ $\mathrm{C} 12$, and $\mathrm{HBPL}_{3600^{-}} \mathrm{C} 18$ and at $80^{\circ} \mathrm{C}$ for $\mathrm{HBPL}_{7500^{-}} \mathrm{C} 8, \mathrm{HBPL}_{7500^{-}}$ C12, HBPL $7500^{-} \mathrm{C} 18$, and $\mathrm{HBPL}_{9600}-\mathrm{C} 12$, respectively. Finally, the annealed film was inserted into the quartz glass cell of a Linkam hot stage. The temperature of the hot stage was regulated by a Linkam CSS450 temperature controller.

Differential Scanning Calorimetry (DSC). Thermal analysis was performed using a Mettler Toledo DSC821 differential scanning calorimeter. Samples between 3 and $5 \mathrm{mg}$ were weighted into 40 $\mu \mathrm{L}$ aluminum pans covered by a holed-cap and analyzed under nitrogen atmosphere. Measurements were performed over a temperature range from 27 to $170{ }^{\circ} \mathrm{C}$ with a heating rate of $10{ }^{\circ} \mathrm{C} /$ min. Since the samples were annealed under high vacuum at 60 or $80{ }^{\circ} \mathrm{C}$ (see annealing procedures described below), the first DSC scan was retained as a valid curve to obtain information on firstand second-order thermodynamic transitions.

Small- and Wide-Angle X-ray Scattering (SWAXS). Simultaneous small and wide-angle X-rays scattering experiments were performed using a SAXSess instrument (Anton Paar) with a line collimation setup. The measurements were carried out in a total angular window ranging between 0.05 and $41^{\circ}$ with the scattering vector being defined as $q=4 \pi / \lambda \sin (\theta / 2)$. The system uses a $\mathrm{Cu}$ $\mathrm{K} \alpha$ radiation source in a sealed tube $(\lambda=0.1542 \mathrm{~nm})$. The beam is attenuated by a semitransparent nickel foil beam stop. A highly sensitive SWAXS imaging plate slide positioned at $264.5 \mathrm{~mm}$ from the sample was used to collect the signal. The temperature of the sample holder could be controlled between -30 and $+200{ }^{\circ} \mathrm{C}$. Liquid samples were injected into a sealed quartz capillary of 1 $\mathrm{mm}$ in diameter, $10 \mu \mathrm{m}$ of wall thickness and a volume of $100 \mu \mathrm{L}$. 


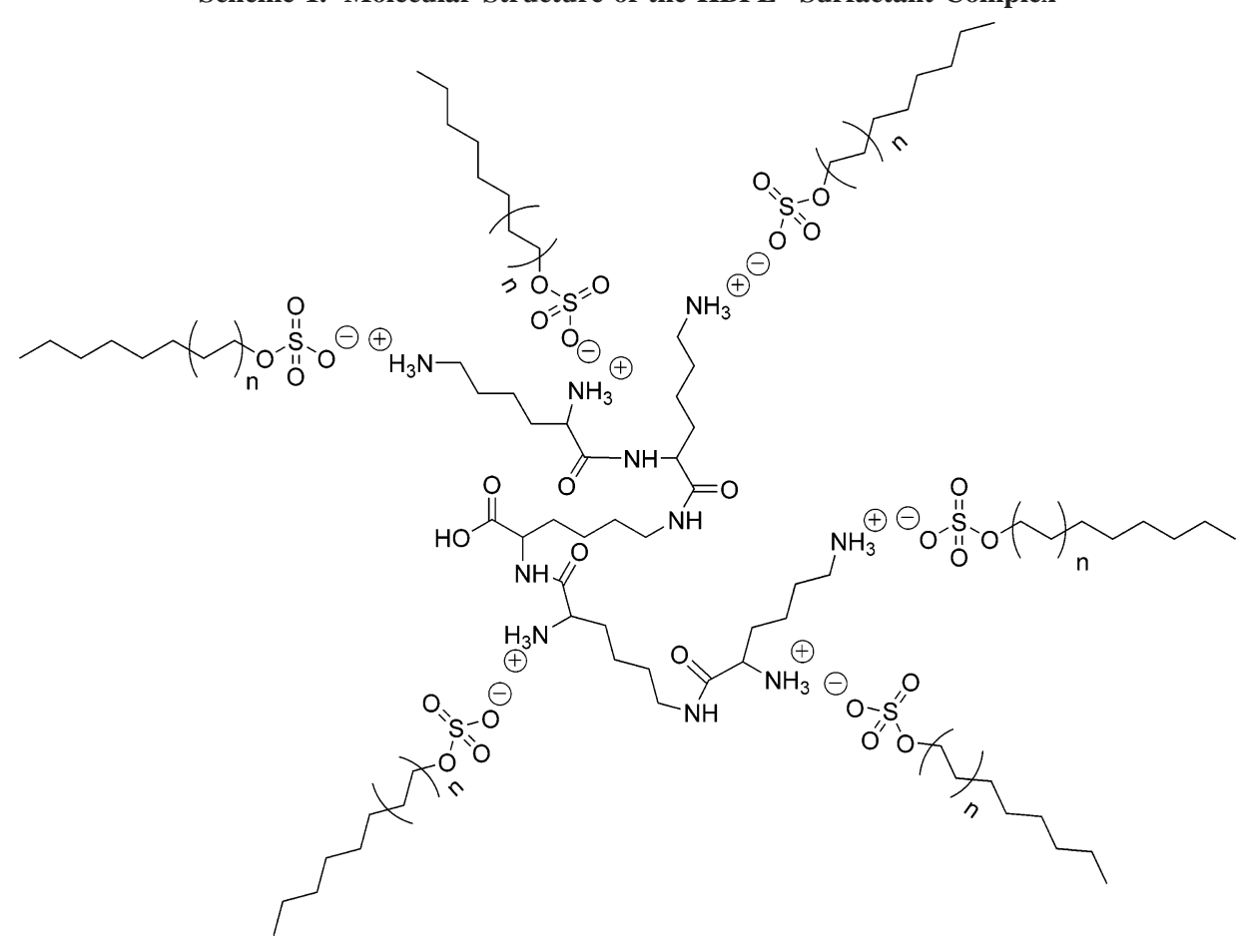

Powder samples were placed between two Kapton foils, which were clamped and sandwiched in a steel sample holder. For dilute solutions, diffraction data were acquired during $12 \mathrm{~h}$, whereas for solid samples, $30 \mathrm{~min}$ of exposure time was sufficient. In temperature-dependent experiments, samples were equilibrated for $1 \mathrm{~h}$ at the given temperature prior to collecting the scattering data. Diffractograms of Kapton and capillaries filled with the appropriate pure solvent were measured as a background for solid samples and solutions, respectively. These backgrounds were then subtracted from the diffractograms to yield the data reported in the present paper. All the scattering signals were treated with SaxSquant software by Anton Paar.

2.3. Procedures. Sample Preparation. A series of HBPLsurfactant complexes was prepared by varying the molecular weight of the HBPL, the nature of the anionic surfactant as well as the molar ratio between the anionic surfactant and the amine groups of the HBPL that was used during the synthesis. A typical procedure is as follows: $1 \mathrm{~g}$ of lyophilized HBPL was dissolved in $50 \mathrm{~mL}$ of water under gentle stirring. $\mathrm{C} 8$ and $\mathrm{C} 12$ were dissolved in water to afford $0.078 \mathrm{M}$ solutions, maintaining the surfactant concentration below the cmc. C18 solution, due to its poor water-solubility, was dissolved in a mixture of 1-butanol/water/ethanol $(87.7 \%$ (wt)/ $10.9 \%$ (wt) $/ 1.3 \%$ (wt)) to afford a $0.064 \mathrm{M}$ solution. The $\mathrm{pH}$ of both the HBPL solution and the surfactant solution was adjusted to a value between 3 and 4, in order to maintain all amino groups of the HBPL positively charged. Once the surfactant solution was prepared, this was dropwise added to the aqueous HBPL solution under continuous stirring. Progressively, the HBPL solution became turbid and the precipitated complex was isolated by centrifugation. When using $\mathrm{C} 8$ and $\mathrm{C} 12$, the collected precipitates were subsequently dissolved in 1-butanol and added dropwise to large excess of acidic water ( $\mathrm{pH} 3-4)$, in order to avoid 1-butanol emulsification in water. This procedure was used to remove eventual excess surfactant, which would then wash out from the precipitate and remain dissolved in the water-butanol phase. This procedure was repeated twice. In the case of $\mathrm{C} 18$, the complex was characterized without further purification, owing to its poor solubility in organic solvents. In order to remove residual water in the final complex, samples, in the form of powder, were dried under vacuum at room temperature for 3 days.

Annealing Process. Prior to characterization, the complexes were annealed for 3 days in a high vacuum column $\left(10^{-8}\right.$ mbar $)$ at a temperature above the glass transition temperature of the HBPL and the melting temperature of the surfactants, but lower than the order/disorder transition temperature $\left(T_{\mathrm{ODT}}\right)$ of the liquid crystalline structure considered. Typically the annealing temperature was $60{ }^{\circ} \mathrm{C}$ for complexes $\mathrm{HBPL}_{3600^{-}} \mathrm{C} 8$, HBPL $\mathrm{H}_{360}-\mathrm{C} 12$ and $\mathrm{HBPL}_{3600} \mathrm{C} 18$ and at $80^{\circ} \mathrm{C}$ for $\mathrm{HBPL}_{7500}$ complexed with $\mathrm{C} 8, \mathrm{C} 12$, and $\mathrm{C} 18$ and for HBPL 9600 complexed with C12.

\section{Results and Discussion}

3.1. Preparation and Characterization of the Hyperbranched Polylysine-Surfactant Complexes. The hyperbranched polymers used in this study have been prepared by $\mathrm{Zr}\left(\mathrm{O}^{\mathrm{n}} \mathrm{Bu}\right)_{4}$ catalyzed thermal polymerization of L-lysine monohydrochloride in the presence of 1 equiv of $\mathrm{KOH} .{ }^{36,37}$ This typically results in hyperbranched polylysines (HBPL) with a number-average molecular weight $\left(M_{\mathrm{n}}\right)$ of $\sim 6000 \mathrm{~g} / \mathrm{mol}$, a degree of branching (DB) of $0.35-0.45$ and an average number of branches (ANB) of 0.15-0.25. For this study, samples with different molecular weights were obtained by dialyzing a sample with $M_{\mathrm{n}}=3900$ against membranes with different molecular weight cut-offs. The HBPL-surfactant complexes were prepared by adding dilute aqueous $(\mathrm{C} 8, \mathrm{C} 12)$ or aqueous $n$-butanol $(\mathrm{C} 18)$ solutions of the surfactants to an aqueous solution of the HBPL (Scheme 1). For a number of HBPL samples, several complexes were prepared by varying the molar ratio between the alkyl sulfate surfactants and the amine groups of the HBPL. The polyelectrolyte complexes were characterized by means of ATR-FTIR and ${ }^{1} \mathrm{H}$ NMR spectroscopy. ATR-FTIR spectroscopy was used to characterize the surfactant, the HBPL and the complex as shown in Figure 1. In the HBPL spectrum, the absorption band at $1550 \mathrm{~cm}^{-1}$ is characteristic for the amide II band, as well as for protonated ammonium groups. The vibration peak at $1643 \mathrm{~cm}^{-1}$ corresponds to the amide I band and to primary amino groups. For all ionic complexes studied, the amine band intensities decreased while the peaks of the sulfate group of the surfactant appeared at 1074, 1207, and $1247 \mathrm{~cm}^{-1}$, respectively, confirming the presence of a HBPL-surfactant complex. Results based on FTIR analysis were further confirmed by ${ }^{1} \mathrm{H}$ NMR spectroscopy, which allowed calculating the degree 


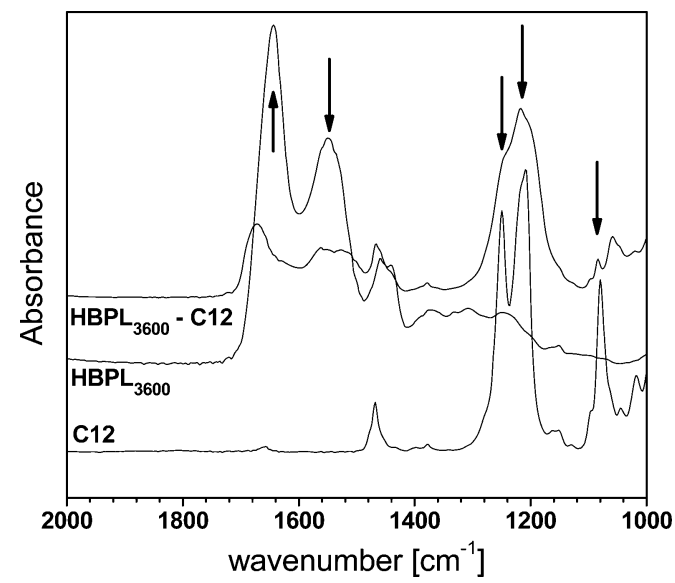

Figure 1. FTIR spectra of the C12 surfactant, $\mathrm{HBPL}_{3600}\left(M_{\mathrm{n}}=3600\right.$ $\mathrm{g} / \mathrm{mol}$ ) and the $\mathrm{HBPL}_{3600}-\mathrm{C} 12$ complex.

of surfactant loading of the HBPL. The degree of loading of the complexes was calculated by comparing the integral of the terminal $\mathrm{CH}_{3}$ group of the surfactant at $0.86 \mathrm{ppm}$ with the combined integrals of the $\epsilon-\mathrm{CH}_{2}$ group of lysine in the hyperbranched polymer at 3.21 and $2.87 \mathrm{ppm}$, respectively. Because of poor solubility in common NMR solvents, the degree of loading for the $\mathrm{C} 18$ complex could not be determined. For the $\mathrm{C} 8$ and $\mathrm{C} 12$ complexes, the degrees of loading were close to 1 , independent of the molecular weight of the polymer and the ratio of surfactant addition as shown in Table 1.

3.2. Solution and Solid-State Characterization. 3.2.1. SWAXS Study on Dilute Solutions. Although a considerable number of studies has been devoted to the investigation of dendrimers in dilute solution, ${ }^{38,39}$ hyperbranched polymers have attracted less attention. ${ }^{40,41}$ In the present study, we have used small-angle X-ray scattering to determine the radius of gyration of both the HBPLs and HBPL-surfactant complexes in good solvent conditions. The HBPLs are soluble in both water and methanol. However, in order to determine the radius of gyration of HBPL, methanol was selected as a solvent, thus avoiding the presence of positive charges on the polymer altering the radius of gyration at rest.

The intensity scattered by a polymer solution can be described as

$$
I(q)=N P(q) S(q)
$$

where $N$ is the number of polymer molecules, $P(q)$ is the form factor of the polymer, and $S(q)$ is the structure factor of the polymer solution. When the system is in the dilute regime, i.e., the polymer molecules are not interacting, the structure factor becomes unity, and the scattered intensity as a function of $q$ is directly proportional to the form factor $P(q)$. Under these conditions, the radius of gyration, $R_{\mathrm{g}}$, can be obtained from $I(q)$ $\sim P(q)$ at very low $q$, where the Guinier regime holds: ${ }^{42,43}$

$$
I(q) / I(0)=P(q)=\exp \left(-q^{2} R_{\mathrm{g}}^{2} / 3\right)
$$

with $I(q) / I(0)$ being the normalized scattered intensity where $I(0)$ is the signal at zero angle. Equation 2, which holds in the limit of $q R_{\mathrm{g}} \ll 1$, yields directly $R_{\mathrm{g}}{ }^{2} / 3$ in a linear regression of $\ln [I(q) / I(0)]$ vs $q^{2}$.

In order to define the Guinier regime for the HBPLs, the scattering intensity at $q=0$ was recorded for a series of progressively diluted solutions of HBPL 7600 in methanol as shown in Figure 2. The scattering intensity at $q=0$ in dilute conditions $(S(q)=1)$ is directly proportional to the number of

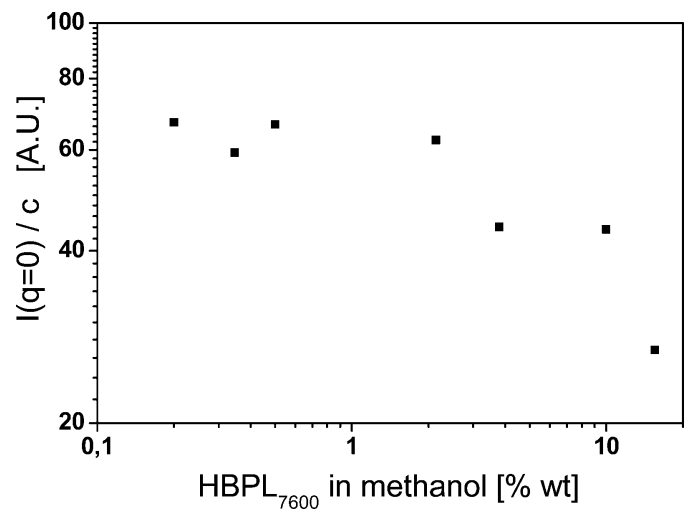

Figure 2. Evolution of the normalized scattering intensity at $q=0$, $I(q=0) / c)$ as a function of the weight fraction of $\mathrm{HBPL}_{7600}$ in methanol solution. The plateau at low concentrations indicates the dilute polymer solution regime.

scattering objects, that is the HBPL polymer molecules, as shown by eq 1 . Therefore, by normalizing $I(0)$ by the weight concentration of polymer, the term $I(0) / c$ reaches a constant value when the polymer molecules become uncorrelated, and thus the dilute conditions required by the Guinier regime are fulfilled. Figure 2 plots $I(0) / c$ for a series of HBPL ${ }_{7600}$ solutions in methanol. At $\sim 1 \%$ weight fraction of the HBPL a plateau is reached showing that dilute conditions have been attained. Six HBPLs with molecular weights ranging between $M_{\mathrm{n}}=3600$ and $9600 \mathrm{~g} / \mathrm{mol}$ and polydispersities between 2.6 and 9.5 and the same HBPLs complexed with $\mathrm{C} 12$ have been characterized by SAXS in the Guinier regime in $0.35 \mathrm{wt} \%$ solutions in methanol for HBPLs alone and $0.25 \mathrm{wt} \%$ solutions in 1-butanol for HBPLs-C12, conditions corresponding in both cases to dilute solutions for all the molecular weights considered. The radius of gyration was obtained by linear regression of $1 n-$ $[I(q) / I(0)]$ vs $q^{2}$ as shown in Figure 3, parts a and b, $I(0)$ was obtained by extrapolation of $I(q)$ curves to $q=0$. The linear regression was fully acceptable for all the HBPLs in the complexed and uncomplexed configuration except for HBPL 3600 and $\mathrm{HBPL}_{3600}-\mathrm{C} 12$ where the scattering signal was systematically noisier for all the repetitive measurements indicing a deviation from 1 of the correlation coefficient $R^{2}$. The influence of the molecular weight on the radius of gyration of the HBPLs and the corresponding C12 complexes is summarized in Figure 4. As expected the $R_{\mathrm{g}}$ increases progressively with the molecular weight from 1.6 to $3.7 \mathrm{~nm}$, although starting at $7500 \mathrm{~g} / \mathrm{mol}$ the $R_{\mathrm{g}}$ reaches a plateau and becomes independent of the molecular weight. Data shown in Figure 4 do not follow a law $R_{\mathrm{g}} \sim M^{\alpha}$ based on a single exponent. This may indicate that the building up of the HBPL structure is changing with molecular weight regime. ${ }^{4-46}$ As expected, the radius of gyration of the HBPLs increases upon complexation for high molecular weight polymer samples. For the polymer sample with $M_{\mathrm{n}}=4400 \mathrm{~g} / \mathrm{mol}$; moreover, the $R_{\mathrm{g}}$ remains unchanged within the experimental error. Furthermore, similarly to pure HBPLs, also in the complex case, the radius of gyration reaches a plateau value of $4 \mathrm{~nm}$ at $7500 \mathrm{~g} / \mathrm{mol}$.

3.2.2. Characterization of the HBPL-Surfactant Complexes in the Bulk State. The organization of the HBPLsurfactant complexes in solid state was characterized by SWAXS, DSC, and cross-polarized optical microscopy. Systematic changes in morphology were achieved by changing the HBPL molecular weight, as well as the length of the surfactant hydrocarbon tail. Three different molecular weights were selected for the hyperbranched polymer, $M_{\mathrm{n}}=3600,7500$, and $9600 \mathrm{~g} / \mathrm{mol}$. 

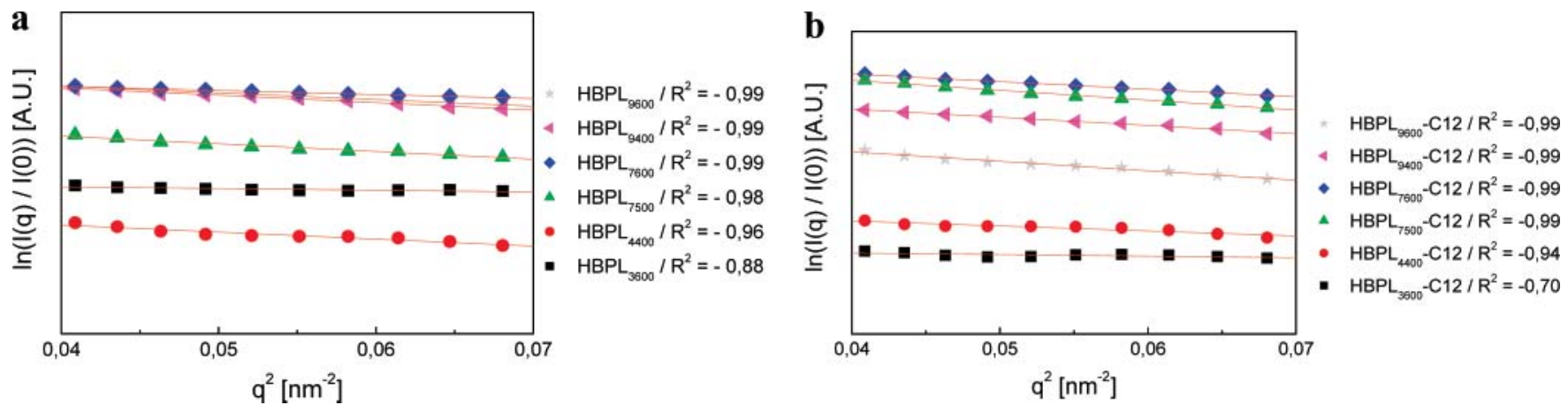

Figure 3. Plot of $\ln \left(I(q) / I_{0}\right)$ vs $q^{2}$ expressing the Guinier regime for (a) $0.35 \%$ (wt) methanol solutions of six HBPLs with molecular weights ranging between $3600 \mathrm{~g} / \mathrm{mol}$ and $9600 \mathrm{~g} / \mathrm{mol}$ and for (b) $0.25 \%$ (wt) 1-butanol solutions of the same six HBPLs complexed with C12. $R^{2}$ corresponds to the correlation coefficient obtained for each linear regression.

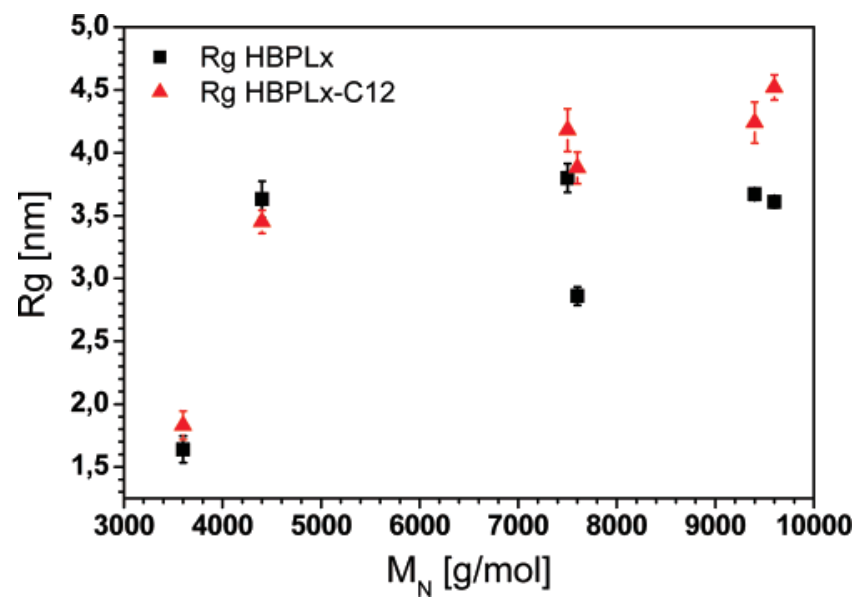

Figure 4. Radii of gyration $\left(R_{\mathrm{g}}\right)$ in methanol as a function of the HBPL molecular weights for HBPL (ם) and the HBPL-C12 complexes (red $\Delta)$.

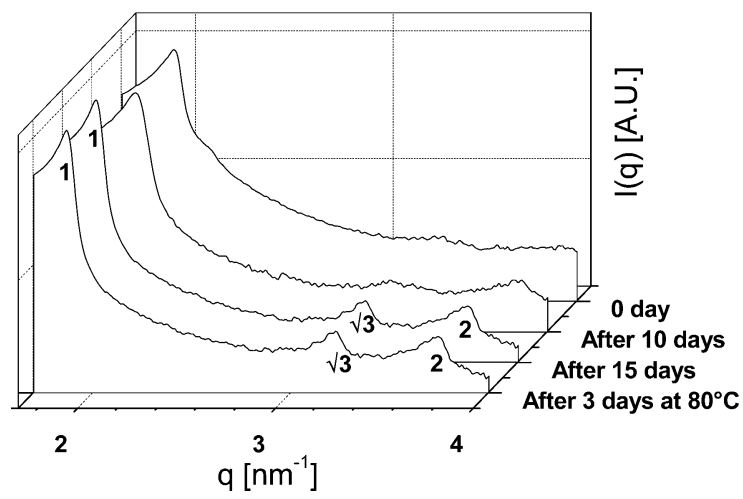

Figure 5. SAXS diffractograms illustrating the annealing effect on the thermodynamic equilibrium of a representative columnar hexagonal phase observed for the HBPL $7500^{-} \mathrm{C} 12$ complex. Two samples have been maintained simultaneously at $120^{\circ} \mathrm{C}$ over 1 day (in order to be in the isotropic state) and at $80{ }^{\circ} \mathrm{C}$ over 3 days. The HBPL ${ }_{7500}-\mathrm{C} 12$ treated at $120{ }^{\circ} \mathrm{C}$ was then cooled down to room temperature and characterized after 0 day (red $\mathbf{\square}), 10$ days (blue $\mathbf{\square}$ ) and 15 days (green $\square$ ) and compared with the sample annealed over 3 days at $80{ }^{\circ} \mathrm{C}$ (gray $\mathbf{\square}$ ).

Before DSC measurements, the samples were annealed to reach the thermodynamic equilibrium. Figure 5 demonstrates that the HBPL ${ }_{7500}-\mathrm{C} 12$ complex needs either 15 days at room temperature to reach the thermodynamic equilibrium columnar hexagonal phase, or 3 days at $80{ }^{\circ} \mathrm{C}$, which validates the annealing protocol followed in the present paper. In view of this result, 3 days was found to be the optimum time for all the

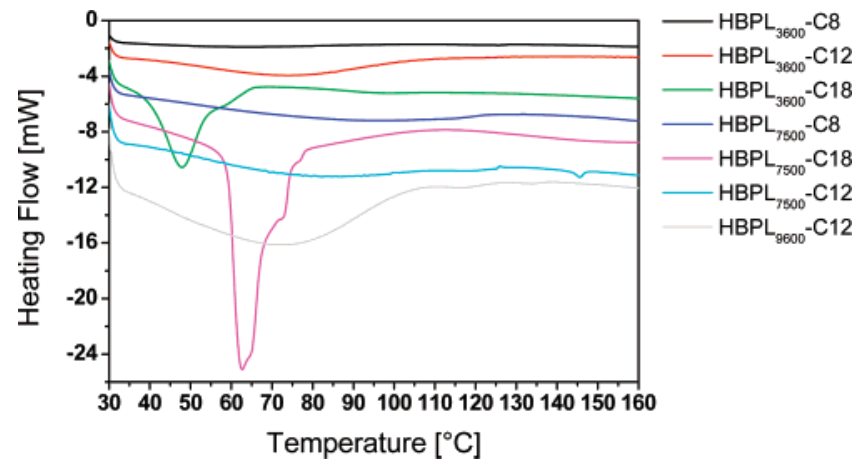

Figure 6. DSC scans at $10{ }^{\circ} \mathrm{C} / \mathrm{min}$ for the following annealed complexes: HBPL (3600 g/mol)-C8 (liquid-like ordered phase), HBPL (3600 g/mol)-C12 (columnar hexagonal phase), HBPL (3600 g/mol)C18 (lamellar phase), HBPL (7500 g/mol)-C18 (lamellar phase), HBPL (3600 g/mol)-C12 (columnar hexagonal phase), HBPL (7500 g/mol)C12 (columnar hexagonal phase), and HBPL (9600 g/mol)-C12 (columnar hexagonal phase).

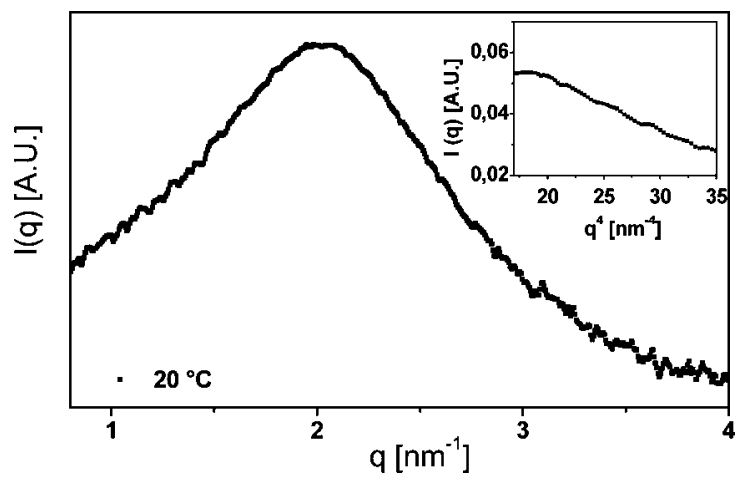

Figure 7. SAXS diffractogram $\left(20^{\circ} \mathrm{C}\right)$ showing for the HBPL-C8 in bulk with HBPL $M_{\mathrm{n}}$ of $7500 \mathrm{~g} / \mathrm{mol}$ a nonbirefringent liquid crystalline phase with short range liquid-like order.

annealing procedures followed in this work. Figure 6 shows the DSC scans of the different HBPL-surfactant complexes. The most remarkable feature in Figure 6 is that the complexes obtained using $\mathrm{C} 18$ surfactant show endothermic melting peaks of the $\mathrm{C} 18$ chains (further confirmed by WAXS data in Figure 11b). In the case of HBPL $7500^{-} \mathrm{C} 18$, the endotherm was followed by a shoulder between $70{ }^{\circ} \mathrm{C}$ and $80^{\circ} \mathrm{C}$, indicative for relaxation phenomena following the melting of the $\mathrm{C} 18$ chains. The HBPL $_{3600}-\mathrm{C} 12$, HBPL $7500-\mathrm{C} 12$, and HBPL $9600-\mathrm{C} 12$ complexes showed very broad endothermic peaks centered at 70, 75, and $85{ }^{\circ} \mathrm{C}$. Cross-polarized optical microscopy allowed additional insight in the thermotropic behavior of the HBPL- 


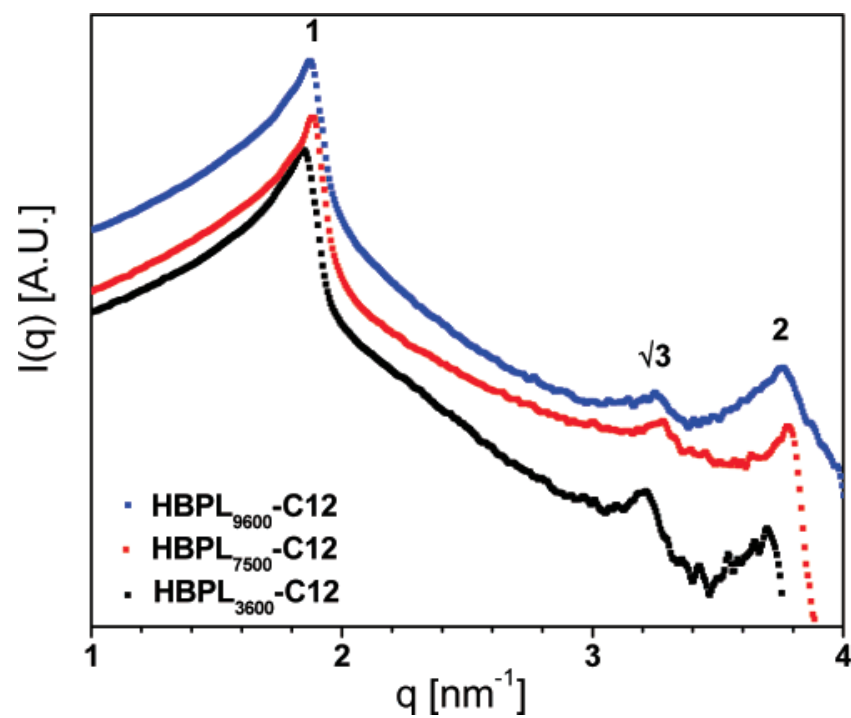

Figure 8. SAXS diffractograms showing the first three reflections typical of a columnar hexagonal phase at room-temperature obtained for the bulk HBPL-C12 complex using three different HBPL $M_{\mathrm{n}}(3600$

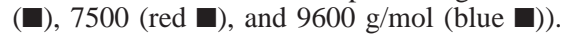

surfactant complexes. HBPL-C8 complexes showed no thermotropic behavior. HBPL-C12 complexes were birefringent at room temperature. The birefringence, however, disappeared at $105{ }^{\circ} \mathrm{C}$ for the $\mathrm{HBPL}_{3600}-\mathrm{C} 12$ complex and at $115^{\circ} \mathrm{C}$ for the HBPL $_{7500}-\mathrm{C} 12$ and $\mathrm{HBPL}_{9600}-\mathrm{C} 12$ samples, indicating that at these temperatures a transition from an anisotropic to isotropic phase occurs. All samples obtained upon complexation of HBPL with $\mathrm{C} 18$ were birefringent until $150^{\circ} \mathrm{C}$ (see Table 2). The lost of birefringency starting $150{ }^{\circ} \mathrm{C}$ is mainly due to the polymer degradation under air, as also confirmed by thermal gravimetric analysis (not shown here).

More detailed and complementary information on phase transitions was obtained by SAXS and WAXS on powder samples of the HBPL-surfactant complexes. Figure 7 shows a single broad-peaked SAXS diffractogram for a complex prepared using the HBPL with $M_{\mathrm{n}}=7500 \mathrm{~g} / \mathrm{mol}$ and the C8 surfactant. This diffractogram cannot be interpreted in terms of the correlation hole arising for comblike systems in the disordered isotropic state, as the asymptotic behavior in proximity of the peak maximum decays as $q^{-4}$ (suggesting microphase separation) rather than as $q^{-2}$, which would indicate structure factor typical of the correlation hole (see inset in Figure 7). ${ }^{47}$ Thus, the single broad peak in Figure 7 and the lack of birefringence, rather indicate that the system adopts a short range liquid-like order with a characteristic correlation distance between the HBPL-surfactant interfaces. Similar liquid-like organization and SAXS diffractograms have been reported both for neutral dendronized homopolymers in bulk $\mathrm{k}^{48,49}$ as well as dendronized polymer-surfactant ionic complexes. ${ }^{15}$ In the case of HBPL-C8 complexes, although the volume fraction of the surfactants estimated by stoichiometric ratio of surfactant and HBPL amine groups is 0.64 , the alkyl chains are too small to induce segregation over long range. Changing the molecular weight of the HBPL neither changes the shape of the diffractogram, nor the location of the maximum at $q$. This indicates that for all HBPL-C8 complexes, the characteristic correlation distance, calculated as $2 \pi / q_{1}=3.14 \mathrm{~nm}$ is not a function of the HBPL molecular weight.

When the length of the surfactant is increased to $\mathrm{C} 12$, the volume fraction of the surfactant units in the complexes is increased to 0.69 and segregation between the HBPL and the surfactant occurs. The corresponding SAXS diffractograms in Figure 8 reveal three reflections at $q_{1}: q_{2}: q_{3}$, spaced as $1: \sqrt{3}: 2$, which is characteristic for a columnar hexagonal phase..$^{50,51} \mathrm{By}$ drawing a tentative analogy with diblock copolymers, ${ }^{52}$ the segregation between the HBPL and the surfactants is now sufficient to induce microphase separation and the volume fraction composition of HBPL and surfactants is asymmetric enough to stabilize a columnar phase in which the interfaces have a specific curvature, and where the minority phase (HBPL) is expected to form the discrete phase.

However, the presence of a columnar hexagonal phase in HBPL - surfactant complexes constitute an unexpected and novel result. Indeed, for the great majority of the LC phases described in literature based on linear polypeptides, only lamellar packing of polypeptide-surfactant complexes has been reported. Thus, the presence of a columnar hexagonal phase in HBPL-C12 complexes must be intimately related to the branched structure of the HBPL polyelectrolyte.

In an hexagonal phase, the in-plane and longitudinal lattice parameters of the unit cell, $a$ and $c$, respectively, are related to the distance $d_{h k l}$ between reflecting planes of $(h k l)$ Miller indexes by the following relation:

$$
\frac{1}{d_{h k l}}=\sqrt{\frac{4}{3} \frac{\left(h^{2}+h k+k^{2}\right)}{a^{2}}+\frac{l^{2}}{c^{2}}}
$$

For objects isotropic along the longitudinal phase, i.e., a columnar hexagonal phase, $l=0$ and taking $d_{h k l}=2 \pi / q$, eq 3 becomes

$$
a=\frac{4 \pi}{q \sqrt{3}} \sqrt{\left(h^{2}+h k+k^{2}\right)}
$$

and the lattice parameter $a$ can be calculated from the $q$ value of the peak corresponding to the first reflection with $(h k l)=$ (100). Table 2 reports the structural parameters for the different HBPL-C12 liquid crystalline phases. It can be noted that the molecular weight has no influence on the lattice parameter. This suggests that the HBPL forms the core of the cylindrical phase, as also expected based on volume fraction considerations, and that the HBPL molecules orient in such a way that they have their cross section orthogonal to the longitudinal axis of the columnar hexagonal phase. Indeed, in the case of surfactants forming the core of the cylinders and the HBPL the continuous phase, the lattice parameter would be expected to depend on HBPL molecular weight. The continuous phase formed by surfactants can then be organized in essentially two different ways: a bilayer with opposite chain ends, or a monolayer with interdigitated alkyl tails. By considering the $\mathrm{C} 12$ surfactant as a fully stretched hydrocarbon tail, the head-to-tail contour length is calculated as $1.6 \mathrm{~nm}$. Then one can obtain the radius of the columnar domains by subtracting the thickness of the monolayer or bilayer surfactant domain from the lattice space of the columnar hexagonal phase and dividing by two. A value of 1.2 $\mathrm{nm}$ is obtained for the radius of the cylinders when interdigitation of the surfactants is assumed.

On the other hand, if a bilayer of surfactant molecules would considered as forming the continuous phase, a value of 0.35 $\mathrm{nm}$ would be calculated for the cylinder radius, which is small enough to rule out the bilayer hypothesis and support the intercalated surfactant model.

The hypothesis of interdigitated alkyl tail chains can be further supported by calculating the radius of cylinders through the volume fraction of HBPL, $\phi=0.31$ and the average lattice 
$\mathbf{a}$

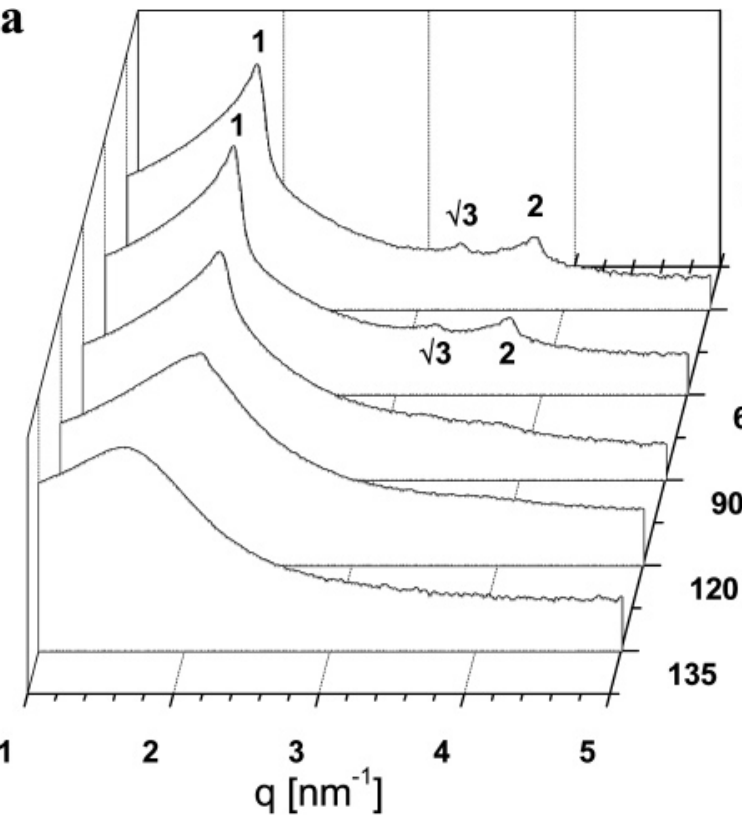

b

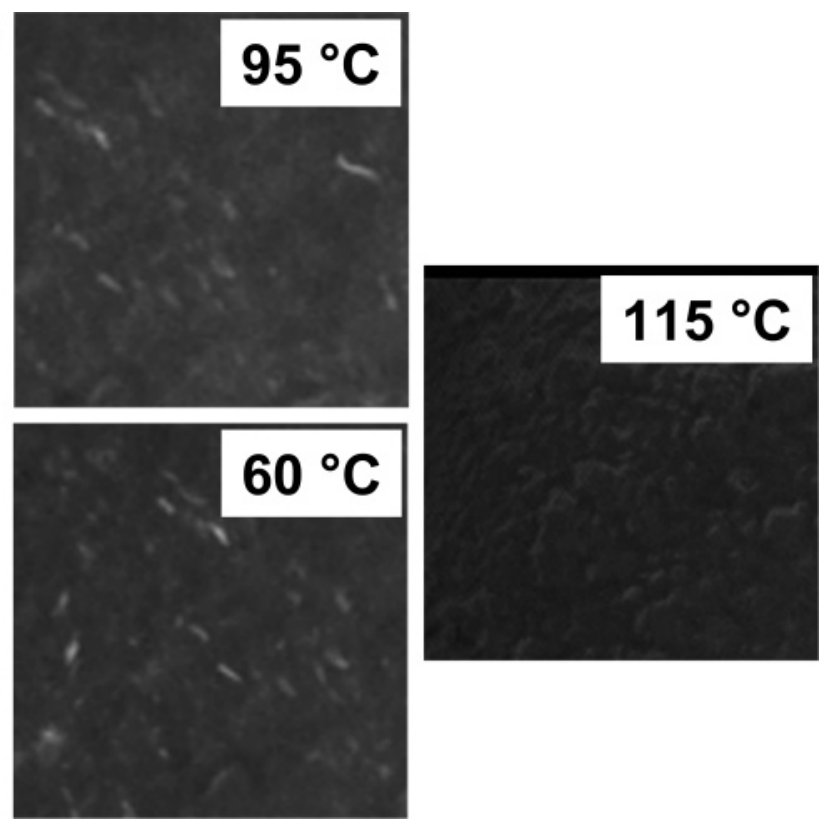

Figure 9. (a) SAXS diffractograms for a HBPL-C12 complex with HBPL $M_{\mathrm{n}}=7500 \mathrm{~g} / \mathrm{mol}$ at various temperatures. At 20 and $60{ }^{\circ} \mathrm{C}$, below the order-nematic transition temperature, $T_{\mathrm{ON}}$, a birefringent columnar hexagonal LC phase is observed. At $90{ }^{\circ} \mathrm{C}$, the hexagonal order is lost, as indicated by the disappearance of the second and third reflections and broadening of the first peak, but the system is still birefringent. At $135^{\circ} \mathrm{C}$, well above the nematic-isotropic transition temperature, $T_{\mathrm{NI}}$, a single-broad peaked diffractogram, is indicative of liquid-like order as supported by the loss of birefringence (b).

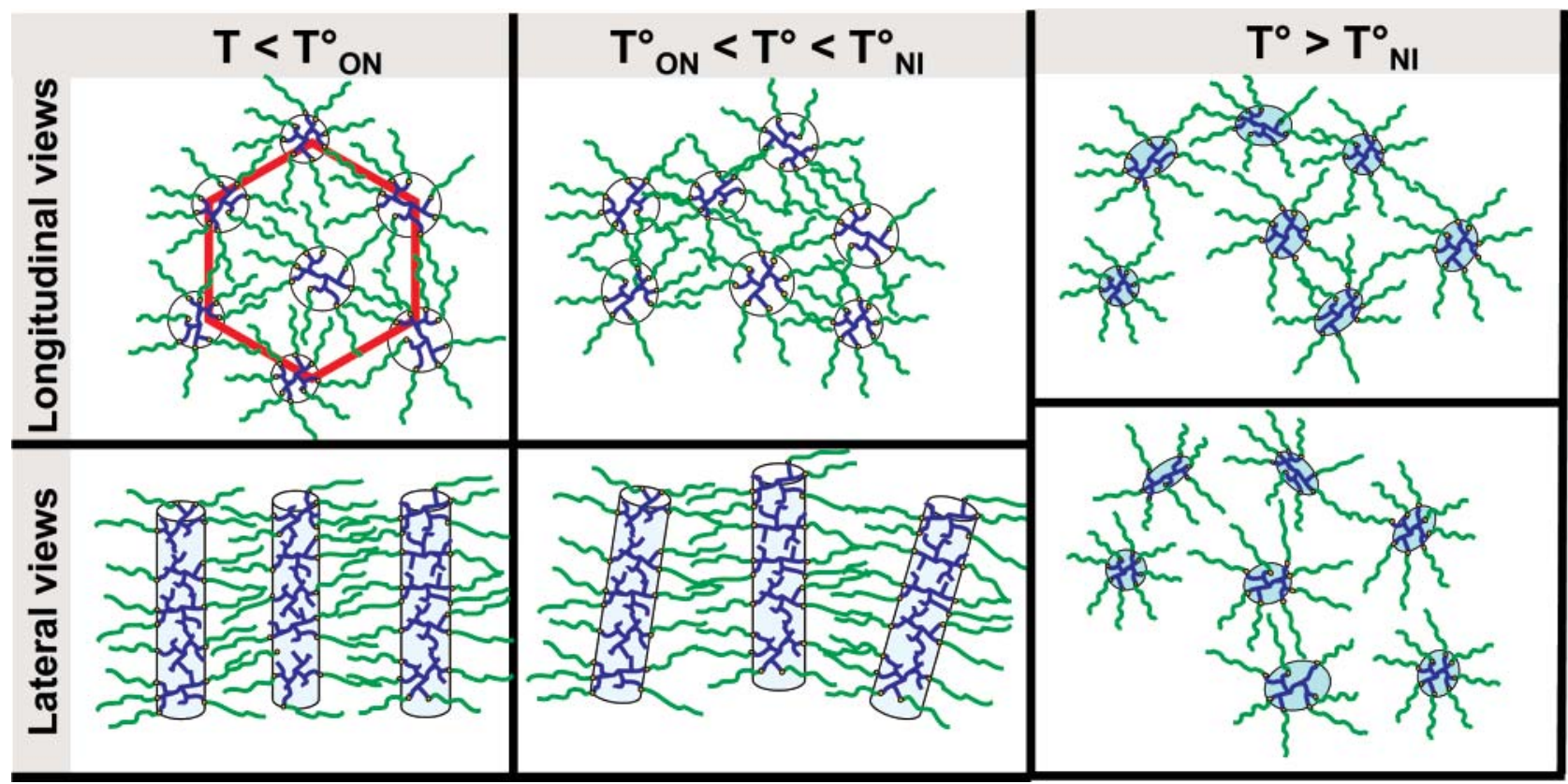

Figure 10. Structural models for the HBPL-C12 complexes at temperatures $T<T_{\mathrm{ON}}, T_{\mathrm{ON}}<T<T_{\mathrm{NI}}$, and $T>T_{\mathrm{NI}}$.

parameter of the columnar hexagonal lattice, $a=3.89 \mathrm{~nm}$ (see Table 2). Then, the radius of cylinders, $r$, can be obtained as

$$
r=a \sqrt{\frac{\sqrt{3}}{2} \frac{\phi}{\pi}}
$$

Since, the value of $\mathrm{r}$ obtained by eq 5 is $1.14 \mathrm{~nm}$, which is only $0.6 \AA$ off the value estimated by supposing interdigitation of alkyl chains $(1.2 \mathrm{~nm})$, it can be reasonably argued that alkyl chains occupy the space in-between cylinders and that they adopt and interdigitated configuration.

With increasing temperature, the columnar hexagonal phase undergoes two structural transitions as revealed by combining
SAXS and cross-polarized optical microscopy. For example, as previously discussed, the hexagonal phase based on HBPL with $M_{\mathrm{n}}=7500 \mathrm{~g} / \mathrm{mol}$ and the $\mathrm{C} 12$ surfactant is stable until 90 ${ }^{\circ} \mathrm{C}$ and birefringent as revealed by CPOM. At this point, the complex remains birefringent, but the hexagonal phase is cleared out, as revealed by the loss of second and third SAXS reflection and the broadening of the first peak (Figure 9). Upon further temperature increase, beyond $115^{\circ} \mathrm{C}$, the birefringence is also lost, and the SAXS diffractogram becomes progressively a single-peaked broad spectrum, characteristic of liquid-like order. This effect can be interpreted in the following way: at $90{ }^{\circ} \mathrm{C}$ the two-dimensional columnar hexagonal structure melts and long-range order is lost. However, HBPL-surfactant interfaces 
$\mathbf{a}$

$\mathbf{a}$

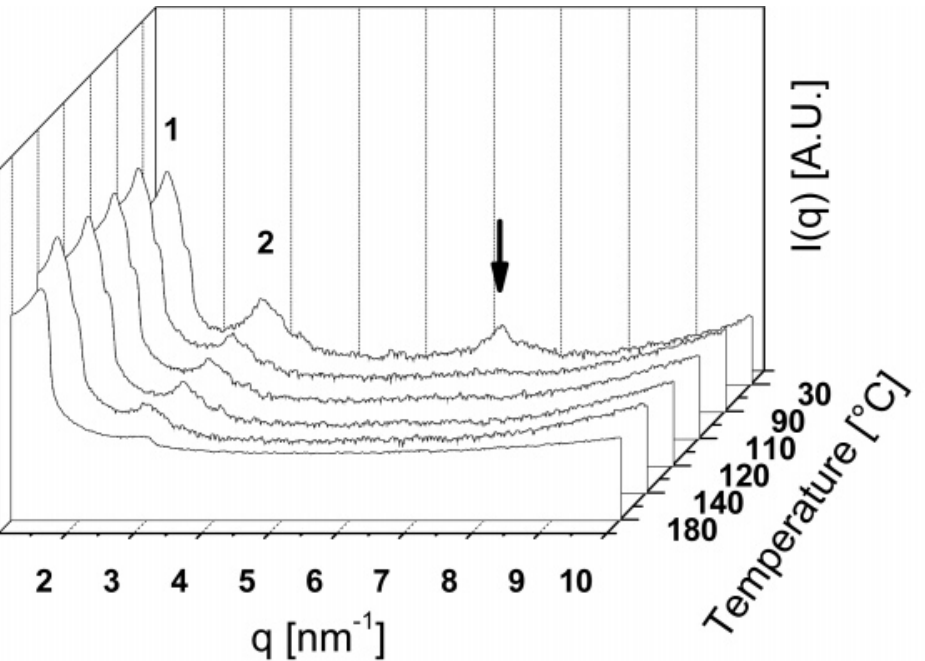

b

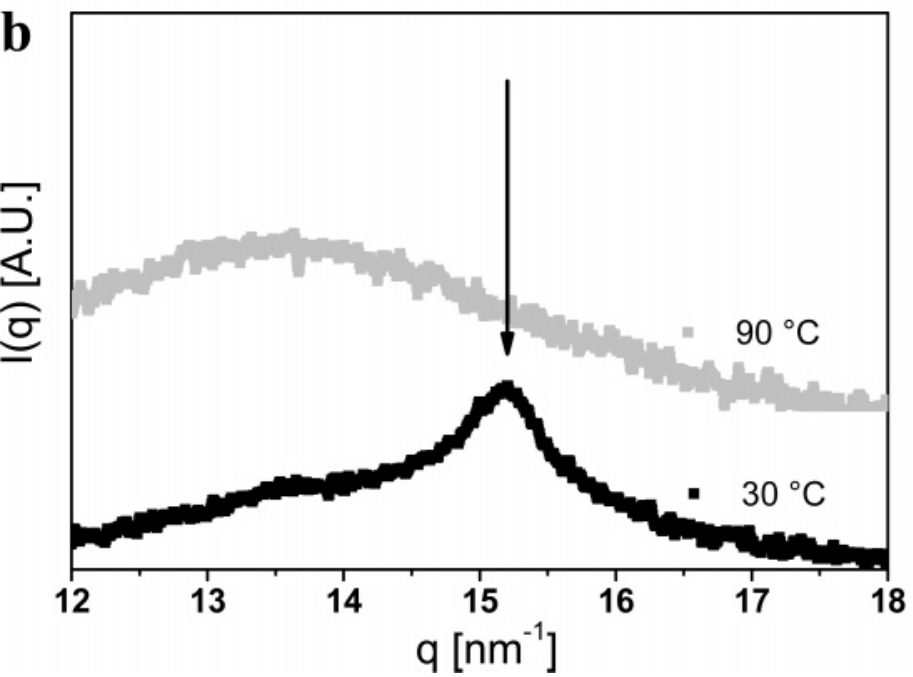

c $135^{\circ} \mathrm{C} \quad 150{ }^{\circ} \mathrm{C}$
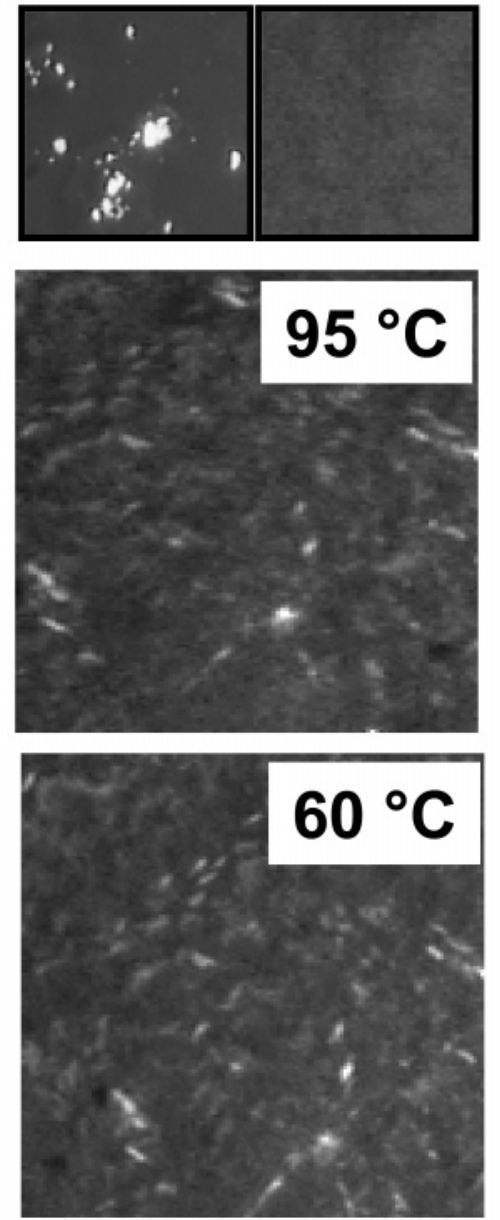

Figure 11. (a) SAXS diffractograms at various temperatures for HBPL-C18 complex with HBPL $M_{\mathrm{n}}=3600 \mathrm{~g} / \mathrm{mol}$ indicating a lamellar phase. The peak at $6.3 \mathrm{~nm}^{-1}$ for the $30^{\circ} \mathrm{C}$ is related to $\mathrm{C} 18$ crystallinity. (b) WAXS diffractogram at room temperature and $90{ }^{\circ} \mathrm{C}$ highlighting melting of crystalline lipid domains. (c) Birefringence observed by cross polarized optical microscopy.

Table 2. Characteristic Data of the Mesophases Formed by Different HBPL-Surfactant Complexes, Which Were Prepared Using Three Different Molecular Weights of HBPL $\left(M_{\mathrm{n}}=3600 \mathrm{~g} / \mathrm{mol}, M_{\mathrm{n}}=7500 \mathrm{~g} / \mathrm{mol}, M_{\mathrm{n}}=9600 \mathrm{~g} / \mathrm{mol}\right)$ and Surfactants with Different Alkyl Chain Lengths $(\mathrm{C8}, \mathrm{C12}, \mathrm{C18})^{a}$

\begin{tabular}{|c|c|c|c|c|c|c|c|}
\hline$M_{\mathrm{n}, \mathrm{HBPLx}} /$ surfactant & $\begin{array}{c}\text { surfactant } \\
\text { vol fraction }\end{array}$ & $\begin{array}{c}(h k l) \text { Miller } \\
\text { indices for Bragg } \\
\text { reflections }\end{array}$ & mesophase & $d[\mathrm{~nm}]$ & $a[\mathrm{~nm}]$ & $\begin{array}{c}\text { ODT }^{1} \\
\text { SWAXS }^{\circ} \\
{\left[{ }^{\circ} \mathrm{C}\right]}\end{array}$ & $\begin{array}{c}\mathrm{ODT}^{2} \\
\mathrm{CPOM} \\
{\left[{ }^{\circ} \mathrm{C}\right]}\end{array}$ \\
\hline $\begin{array}{l}3600 / \mathrm{C}_{8} \\
7500 / \mathrm{C}_{8}\end{array}$ & 0.64 & \multicolumn{6}{|c|}{ short range liquid-like order } \\
\hline $3600 / \mathrm{C}_{12}$ & 0.69 & (100), (110), (200) & hexagonal & 3.42 & 3.95 & 80 & 105 \\
\hline $7500 / \mathrm{C}_{12}$ & & & & 3.33 & 3.85 & 90 & 115 \\
\hline $9600 / \mathrm{C}_{12}$ & & & & 3.34 & 3.86 & 90 & 115 \\
\hline $3600 / \mathrm{C}_{18}$ & 0.74 & (100), (200) & lamellar & 4.91 & & $>180$ & $>150$ \\
\hline $7500 / \mathrm{C}_{18}$ & & & & 4.90 & & & \\
\hline
\end{tabular}

${ }^{a} d$ is the Bragg distance, $a$ is the lattice parameter. $\mathrm{ODT}^{1}$ and $\mathrm{ODT}^{2}$ are the order-nematic and nematic-isotropic transitions determined by SWAXS and CPOM, respectively. Surfactant volume fractions were estimated assuming densities of $1 \mathrm{~g} / \mathrm{cm}^{3}$ for the HBPL and the surfactants.

with a well-defined electron density contrast are still oriented along a common director, providing to the system a birefringent nematic liquid crystallinity. Additional energy will be then required to clear-out this orientation, and beyond $115^{\circ} \mathrm{C}$ the system will become isotropic and thus nonbirefringent. Accordingly, the first transition temperature is therefore called ordernematic transition temperature, $T_{\mathrm{ON}}$, while the second one is referred as nematic-isotropic transition temperature, $T_{\mathrm{NI}}$. Again, the complex thermotropic behavior of the present hexagonal phase, differs markedly from the typical temperature-dependent behavior of linear polypeptide-surfactant complexes, which, tend to form lamellar phases whose structural behavior seem to be rather independent of temperature. ${ }^{30}$ Figure 10 illustrates schematically the structural models of the HBPL-C12 complex at temperatures $T<T_{\mathrm{ON}}, T_{\mathrm{ON}}<T<T_{\mathrm{NI}}$ and $T>T_{\mathrm{NI}}$.

When the surfactant length is increased to $\mathrm{C} 18$, the tendency toward microsegregation is further enhanced and the surfactant volume fraction increases to 0.74 . The corresponding SAXS diffractogram of the HBPL-C18 complex showed two peaks $q_{1}: q_{2}$, spaced as $1: 2$, which is characteristic of a lamellar phase, as shown in Figure 11a. Figure 11a also shows that at low temperature, a third peak appears at $q=6.3 \mathrm{~nm}^{-1}$ accompanied 


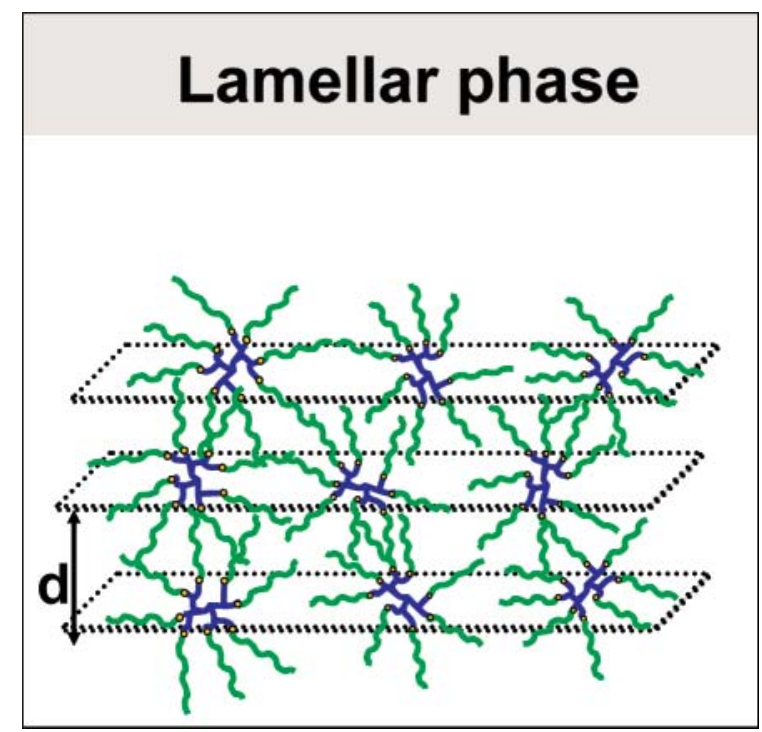

Figure 12. Structural model for the HBPL-C18 complexes in bulk.

by sharps peaks in the region of $q=12-16 \mathrm{~nm}^{-1}$, which indicates crystallinity of the surfactant domains, as also confirmed by DSC data. The dominant crystallization peak in the wide angle region at real Bragg spacing of $4.2 \AA$ (see Figure 11b) indicates that, within the lamellar layers, the alkyl tails crystallize in a hexagonal lattice. ${ }^{30}$ By increasing the temperature, the peaks at large $q$, characteristic of the surfactant crystallinity were lost, indicating melting of the surfactant phase, while the two peaks of the lamellar phase were maintained up to $180{ }^{\circ} \mathrm{C}$, without significant change in position, indicating that the crystallization/melting of the lipid phase does not interfere with formation of the lamellar phase. The birefringence finally disappears at $150{ }^{\circ} \mathrm{C}$, as a consequence of polymer degradation in air (Figure 11c).

The lattice parameter of the lamellar phase extracted by SAXS diffractograms as $a=2 \pi / q_{1}$ was $4.9 \mathrm{~nm}$ independent of the molecular weight of the HBPL used, similarly to what is observed for the hexagonal phase. This confirms that also in the lamellar phase the HBPL chains align with their main backbone parallel to the lamellar planes. A rough calculation of the thickness of the HBPL and alkyl tails domains is possible by weighting the lattice parameter of the lamellar phase by the corresponding volume fractions. Then, a width of 1.3 and $3.6 \mathrm{~nm}$ is obtained for HBPL and alkyl tail domains, respectively. By comparing the estimated width of alkyl tails domains $(3.6 \mathrm{~nm})$ with the contour length of fully stretched C18 alkyl tails $(2.44 \mathrm{~nm})$, partially interdigitated or tilted chains can be expected. Furthermore, by comparing the width of the HBPL layers $(1.3 \mathrm{~nm})$ with the diameter of HBPL cylinders in the hexagonal phases $(2.4 \mathrm{~nm})$, it could be argued that the HBPL polymers must adopt a compressed packing within the lamellar layers. The proposed structural model for the HBPL-C18 LC phase is sketched in Figure 12. In the sketch, a partially interdigitated alkyl chain configuration has been assumed.

On the basis of the results discussed above, it can be concluded that a minimum length of the hydrocarbon chain of the surfactant, $\mathrm{C} x>\mathrm{C} 8$, is required in order to induce longrange microsegregation between the HBPL and the surfactant domains. When this critical level for microsegregation is achieved and microphase segregation takes place, columnar hexagonal or lamellar thermotropic liquid crystalline phases are formed, depending on the length of the surfactant.

\section{Conclusions}

We have described the solution and solid-state structural organization of supramolecular assemblies of cationic hyperbranched polypeptides and anionic surfactants, as revealed by small and wide-angle X-ray scattering, differential scanning calorimetry and cross-polarized optical microscopy. The radius of gyration in a good solvent for both the hyperbranched peptides and the corresponding surfactant complexes was shown to increase with the molecular weight of the HBPL, but reached a plateau value of 3.7 and $4.0 \mathrm{~nm}$ for the HBPL and the HBPL complex, respectively, when a molecular weight of the HBPL of the order of $7500 \mathrm{~g} / \mathrm{mol}$ was attained. Analysis of the solidstate properties of HBPL-surfactant complexes revealed the formation of liquid crystalline phases due to segregation of the surfactant chains and HBPL polymer. When a surfactant with a short hydrocarbon tail was used (C8), the segregation was too small to induce long range microphase separation and liquid crystalline phases with short range liquid-like order were observed. However, with increasing surfactant chain length, a columnar hexagonal phase and a lamellar phase were observed, when the hydrocarbon chain was composed of 12 or 18 carbons (C12 and $\mathrm{C} 18$, respectively). The presence of a columnar hexagonal phase has no analogue in the homologue studies of linear homopolypeptide-surfactant complexes. By comparing the lattice parameter obtained by SAXS with the length of fully stretched surfactant chains and the radius of gyration of HBPL, we could argue that the surfactants form a monolayer with interdigitated surfactant chains in the columnar hexagonal phase and partially interdigitated or tilted alkyl tails in the lamellar phase. From the independence of the lattice parameter on the HBPL molecular weight, it was concluded that the HBPL molecules orient with their cross section orthogonal to the columnar longitudinal axis and lamellar planes, respectively. Finally, by combining cross-polarized optical microscopy with $\mathrm{X}$-ray scattering, two different types of structural transitions were shown to occur at two different temperatures. The first, at $T_{\mathrm{ON}}$, corresponded to an order-nematic transition, or in other words, the melting of two-dimensional columnar hexagonal order with persistence of the alignment of interfaces along a common director. When the temperature was increased further to $T_{\mathrm{NI}}$, the alignment of interfaces was also lost, and the system underwent a nematic-isotropic transition, with complete loss of birefringence. The HBPL molecular weight did not affect the mesophase structure, nor the lattice space, but contributed to rise $T_{\mathrm{ON}}$ and $T_{\mathrm{NI}}$, while polydispersity of the HBPL was shown to have the opposite effect. On the basis of these findings, structural models for the HBPL-lipid complex organization in the solid state were proposed at temperatures $T<T_{\mathrm{ON}}, T_{\mathrm{ON}}<$ $T<T_{\mathrm{NI}}$, and $T>T_{\mathrm{NI}}$.

Acknowledgment. We are grateful to Prof. P. Schurtenberger for fruitful and stimulating discussions. Dr. J. N. Aebischer of the Engineer School of Fribourg is acknowledged for allowing the use of the differential scanning calorimeter and Dr. T. Q. Nguyen for the GPC measurements. The Swiss Science National Foundation (N.C. and R.M.) and BASF AG (M.S. and H.-A.K.) are acknowledged for financial support.

\section{References and Notes}

(1) Leibler, L. Macromolecules 1980, 13, 1602-1617.

(2) Bates, F. S.; Fredrickson, G. H. Annu. Rev. Phys. Chem. 1990, 41, 525-557.

(3) Stadler, R.; Auschra, C.; Beckmann, J.; Krappe, U.; Voigt-Martin, I.; Leibler, L. Macromolecules 1995, 28, 3080-3097. 
(4) Fredrickson, G. H.; Ganesan, V.; Drolet, F. Macromolecules 2002, $35,16-39$.

(5) Ruokolainen, J.; ten Brinke, G.; Ikkala, O. Adv. Mater. 1999, 11, 777780 .

(6) Valkama, S.; Lehtonen, O.; Lappalainen, K.; Kosonen, H.; Castro, P.; Repo, T.; Torkkeli, M.; Serimaa, R.; ten Brinke, G.; Leskelä, M.; Ikkala, O. Macromol. Rapid Commun. 2003, 24, 556-560.

(7) ten Brinke, G.; Ikkala, O. Chem. Rec. 2004, 4, 219-230.

(8) Antonietti, M.; Conrad, J.; Thünemann, A. Macromolecules 1994, 27, 6007-6011.

(9) Faul, C. F. J.; Antonietti, M. Adv. Mater. 2003, 15, 673-683.

(10) Ruokolainen, J.; Mäkinen, R.; Torkkeli, M.; Mäkelä, T.; Serimaa, R.; ten Brinke, G.; Ikkala, O. Science 1998, 280, 557-560.

(11) Ikkala, O.; ten Brinke, G. Science 2002, 295, 2407-2409.

(12) Ikkala, O.; ten Brinke, G. Chem. Commun. 2004, 2131-2137.

(13) Martín-Rapún, R.; Marcos, M.; Omenat, A.; Barberá, J.; Romero, P.; Serrano, J. L. J. Am. Chem. Soc. 2005, 127, 7397-7403.

(14) Canilho, N.; Kasëmi, E.; Mezzenga, R.; Schlüter, A. D. J. Am. Chem. Soc. 2006, 128, 13998-13999.

(15) Canilho, N.; Kasëmi, E.; Schlüter, A. D.; Mezzenga, R. Macromolecules 2007, 40, 2822-2830.

(16) Antonietti, M.; Burger, C.; Effing, J. Adv. Mater. 1995, 7, 751-753.

(17) Guan, Y.; Antonietti, M.; Faul, C. F. J. Langmuir 2002, 18, 59395945 .

(18) Kim, Y. H. J. Am. Chem. Soc. 1992, 114, 4947-4948.

(19) Bauer, S.; Ringsdorf, H.; Fischer, H. Angew. Chem., Int. Ed. Engl. 1993, 32, 1589-1592.

(20) Lorenz, K.; Hölter, D.; Stühn, B.; Mülhaupt, R.; Frey, H. Adv. Mater. 1996, 8, 414-416.

(21) Pesak, D. J.; Moore, J. S. Angew. Chem., Int. Ed. Engl. 1997, 36, 1636-1639.

(22) Percec, V.; Cho, W.-D.; Möller, M.; Prokhorova, S. A.; Ungar, G.; Yeardley, D. J. P. J. Am. Chem. Soc. 2000, 122, 4249-4250.

(23) Zeng, X.; Ungar, G.; Liu, Y.; Percec, V.; Dulcey, A. E.; Hobbs, J. K. Nature (London) 2004, 428, 157-160.

(24) Park, C.; Choi, K. S.; Song, Y.; Jeon, H.-J.; Song, H. H.; Chang, J. Y.; Kim, C. Langmuir 2006, 22, 3812-3817.

(25) Artzner, F.; Zantl, R.; Rapp, G.; Rädler, J. O. Phys. Rev. Lett. 1998, $81,5015-5018$

(26) Gallot, B.; Diao, T. Polymer 1992, 33, 4052-4057.

(27) Gallot, B.; Fafiotte, M.; Fissi, A.; Pieroni, O. Macromol. Rapid Commun. 1996, 17, 493-501.

(28) Chécot, F.; Brûlet, A.; Oberdisse, J.; Gnanou, Y.; Mondain-Monval, O.; Lecommandoux, S. Langmuir 2005, 21, 4308-4315.

(29) Ponomarenko, E. A.; Waddon, A. J.; Bakeev, K. N.; Tirrell, D. A.; MacKnight, W. J. Macromolecules 1996, 29, 4340-4345.

(30) MacKnight, W. J.; Ponomarenko, E. A.; Tirrell, D. A. Acc. Chem. Res. 1998, 31, 781-788.
(31) Liu, J.; Takisawa, N.; Kodama, H.; Shirahama, K. Langmuir 1998 , 14, 4489-4494.

(32) Kukula, H.; Schlaad, H.; Antonietti, M.; Forster, S. J. Am. Chem. Soc. 2002, 124, 1658-1663.

(33) Roscigno, P.; D’Auria, G.; Falcigno, L.; D’Errico, G.; Paduano, L. Langmuir 2005, 21, 8123-8130.

(34) Hanski, S.; Houbenov, N.; Ruokolainen, J.; Chondronicola, D.; Iatrou, H.; Hadjichristidis, N.; Ikkala, O. Biomacromolecules 2006, 7, 33793384.

(35) Quina, F. H.; Nassar, P. M.; Bonilha, J. B. S.; Bales, B. L. J. Phys. Chem. 1995, 99, 17028-17031.

(36) Scholl, M.; Nguyen, T. Q.; Bruchmann, B.; Klok, H.-A. Macromolecules, 2007, 40, 5726-5734.

(37) Scholl, M.; Nguyen, T. Q.; Bruchmann, B.; Klok, H.-A. J. Polym. Sci., Part A: Polym Chem. 2007, in press.

(38) Prosa, T. J.; Bauer, B. J.; Amis, E. J.; Tomalia, D. A.; Scherrenberg, R. J. Polym. Sci., Part B: Polym. Phys. 1997, 35, 2913-2924.

(39) Pötschke, D.; Ballauff, M.; Lindner, P.; Fischer, M.; Vögtle, F. J. Appl. Crystallogr. 2000, 33, 605-608.

(40) Sheridan, P. F.; Adolf, D. B.; Lyulin, A. V.; Neelov, I.; Davies, G. R. J. Chem. Phys. 2002, 117, 7802-7812.

(41) Garamus, V. M.; Maksimova, T. V.; Kautz, H.; Barriau, E.; Frey, H.; Schlotterbeck, U.; Mecking, S.; Richtering, W. Macromolecules 2004, 37, 8394-8399.

(42) Ghosh, S. K.; Kawaguchi, S.; Jinbo, Y.; Izumi, Y.; Yamaguchi, K.; Taniguchi, T.; Nagai, K.; Koyama, K. Macromolecules 2003, 36, 9162-9169.

(43) Choi, J.; Kwak, S.-Y. Macromolecules 2003, 36, 8630-8637.

(44) Lescanec, R. L.; Muthukumar, M. Macromolecules 1990, 23, 22802288.

(45) Mourey, T. H.; Turner, S. R.; Rubinstein, M.; Fréchet, J. M. J.; Hawker, C. J.; Wooley, K. L. Macromolecules 1992, 25, 2401-2406.

(46) Scherrenberg, R.; Coussens, B.; van Vliet, P.; Edouard, G.; Brackman, J.; de Brabander, E.; Mortensen, K. Macromolecules 1998, 31, 456461.

(47) Huh, J.; Ikkala, O.; ten Brinke, G. Macromolecules 1997, 30, 18281835.

(48) Zhang, A.; Okrasa, L.; Pakula, T.; Schlüter, A. D. J. Am. Chem. Soc. 2004, 126, 6658-6666.

(49) Zhang, B.; Zhang, S.; Okrasa, L.; Pakula, T.; Stephan, T.; Schmidt, M. Polymer 2004, 45, 4009-4015.

(50) Pisula, W.; Tomović, Z.; Simpson, C.; Kastler, M.; Pakula, T.; Müllen, K. Chem. Mater. 2005, 17, 4296-4303.

(51) Mezzenga, R.; Meyer, C.; Servais, C.; Romoscanu, A. I.; Sagalowicz, L.; Hayward, R. C. Langmuir 2005, 21, 3322-3333.

(52) Matsen, M. W.; Bates, F. S. Macromolecules 1996, 29, 1091-1098. 